\title{
Pesta Kerja Tahun Masyarakat Karo di Desa Batu Karang Kecamatan Payung Kabupaten Karo
}

\author{
Emia Ariska Br Purba ${ }^{1}$, Adri Febrianto ${ }^{2}$ \\ ${ }^{1,2}$ Universitas Negeri Padang \\ Email: ariskaemia@yahoo.com
}

\begin{abstract}
Abstrak
Artikel ini bertujuan untuk mendeskripsikan simbol dan makna yang terdapat pada Pesta kerja tahun di Desa Batu Karang Kecamatan Payung Kabupaten Karo yang merupakan ucapan syukur terhadap hasil panen. Pesta kerja tahun dilakukan setiap tahun di bulan Januari pada hari Cukra dudu dalam penanggalan kalender Karo. Pesta kerja tahun dilaksanakan selama dua hari pada saat pagai beltek. Penelitian dilakukan dengan pendekatan kualitatif dengan tipe etnografi. Data dikumpulkan dengan wawancara mendalam, observasi partisipasi dan studi dokumen. Data di analisa dengan menggunakan analisa interpretif dari Clifford Geertz. Temuan penelitian mengungkapkan makan simbol secara emik dan etik. Makna upacara pesta kerja tahun (emik) terdiri dari 1). Makna simbol pemakaian kalender Karo dalam penetapan tanggal pesta kerja tahun 2) Simbol kepemimpinan dan makna dari pembentukan panitia 3) Makna dan simbol sumbangan dana dari masyarakat Desa Batu Karang 4) Makna simbol ngerires dan mantem, 5) Makna simbol festival tari telu serangkai dan vocal solo, 6) Makna simbol dari kirumah-kirumah, 7) Makna gendang guro-guro aron, 8) Makna simbol ngerebu. Makna upacara Pesta Kerja Tahun secara etik yaitu: pengatakenbujun man Tuhan, Mara klesa. Makna Pesta Kerja Tahun sebagai hiburan, Sarana pendidikan dan pelestarian budaya Karo tempat mencari Jodoh.
\end{abstract}

Kata kunci: Kerja Tahun, Makna, Simbol, Upacara

\section{Abstract}

This article aims to describe the symbols and meanings contained in the annual work party in Batu Karang Village, Payung District, Karo Regency which is a thanksgiving for the harvest. The annual work party is held annually in January on the day of Cukra dudu in the Karo calendar. The annual work party is held for two days during pagai beltek. The research was conducted with a qualitative approach with ethnographic type. Data were collected by in-depth interviews, participatory observation and document study. Data were analyzed using the interpretive analysis of Clifford Geertz. The research findings reveal that eating symbols is emic and ethical. The meaning of the annual work ceremony ceremony (emik) consists of 1). The meaning of the symbol for the use of the Karo calendar in determining the date of the work party in the year 2) The symbol of leadership and the meaning of the formation of the committee 3) The meaning and symbol of the donation of funds from the people of Batu Karang Village 4) The meaning of the symbol of ngerires and mantem, 5) The meaning of the symbol of the telu serangkai dance festival and vocals solo, 6) The meaning of the symbol from kirumah-kirumah, 7) The meaning of the gendang guro-guro aron, 8) The meaning of the symbol ngerebu. The ethical meaning of the Year Work Party ceremony, namely: pengatakenbujun man God, Mara klesa. The meaning of the Year Work Party as entertainment, educational facilities and preservation of Karo culture as a place to find a mate. Key Words: Ceremonial, Kerja Tahun, Meanings, Symbols

\begin{tabular}{l|l|l} 
Received: December 8, 2020 & Revised: December 29, 2020 & Published: December 30, 2020 \\
\hline
\end{tabular}

Culture \& Society: Journal of Anthropological Research Vol. 2, No. 2, Th. 2020 


\section{Pendahuluan}

Keberadaan upacara sebagai bagian dari kebudayaan sebuah masyarakat tidak dapat terpisahkan, begitu pula dengan upacara adat yang ada pada masyarakat Karo. Masyarakat Karo sebagai salah satu suku bangsa di Nusantara memiliki berbagai macam budaya yang hidup dan dipertahankan di tengah-tengah masyarakat baik berupa sistem kepercayaan (religi), kesenian, sistem pengetahuan mata pencaharian, bahasa, organisasi sosial, sistem peralatan dan teknologi (Koentjaraningrat, 1992). Masyarakat Karo tetap melaksanakan tradisi pesta kerja tahun sebagai rangkaian dari sistem ekonomi atau produksi masyarakat dan sistem religi mereka.

Upacara pesta kerja tahun sejak dahulunya harus mengikuti adat dan aturan (pranata) (Koentjaraningrat, 1992), nenek moyang masyarakat Karo, walaupun sekarang terdapat berbagai pergeseran dan perubahan tata pelaksanaan upacara pesta kerja tahun tetap dilaksanakan. Sama halnya dengan masyarakat Desa Batu Karang juga mengikuti upacara pesta kerja tahun. Pesta kerja tahun di Desa Batu Karang ini memiliki perbedaan dengan kebanyakan Desa di Tanah Karo. Pelaksanaan pesta kerja tahun dilaksanakan pada bulan Januari setiap tahunnya pada saat pagai beltek dan dilaksanaan di setiap wari cukra dudu lau dalam penanggalan kalender Karo karena diyakini hari cukra $d u d u$ adalah hari yang paling baik untuk melakukan pesta meskipun pada bulan Januari tersebut padi belum panen, tapi masyarakat Desa Batu Karang tetap melakukan Tradisi ini, pesta kerja tahun ini merupakan ucapan syukur kepada beru dayang karena masih menjaga padi dan pengharapan agar hasil panen melimpah. Selain itu masyarakat Desa Batu Karang juga Masih mengikuti hari ngerebu yang sudah banyak dilupakan oleh masyarakat Karo.

Pembentukan tanggal untuk pesta kerja tahun di Desa Batu Karang juga mempunyai ketentuan sendiri yaitu penetapan hari di wari cukra dudu serta rangkaian pelaksanaan pesta kerja tahun di masyarakat Desa Batu Karang adalah ngerires dan mantem yang dilaksanakan pada pesta kerja tahun hari yang pertama yang dilakukan dari pagi hingga sore hari. Masyarakat Desa Batu Karang hanya membuat rires sebagai makanan pada saat pesta kerja tahun berbeda dengan desadesa yang lain yang menambah menu makanan cimpa dan tape pada saat acara pesta kerja tahun. Sedangken mantem biasanya hampir setiap daerah memotong babi untuk lauk pesta kerja tahun. Untuk malam harinya masyarakat Desa Batu Karang beramai-ramai berdatangan ke Jambur untuk menyaksikan acara festival tari telu serangkai dan vocal solo.

Pada hari kedua merupakan masyarakat Desa Batu Karang saling bersilaturahmi antar kerabat, baik kerabat yang masih satu desa maupun yang datang dari luar desa yang datang sebagai temue (tamu) untuk merayakan dan memeriahkan upacara pesta kerja tahun yang sedang berlangsung. Dari pagi hingga sore hari masyarakat khususnya tamu yang berkunjung ke rumah salah seorang warga Desa Batu Karang akan disuguhkan jamuan adat Karo yakni makanan yang telah dibuat pada waktu ngerires dan mantem. Pada hari ketiga biasanya masyarakat Desa Batu Karang akan istirahat sejenak dari rutinitas pekerjaan mereka, hal ini dikenal dengan istilah ngerebu.

Penelitian relevan sudah dilakukan oleh Novaria Elviyanti Barus pada tahun 2013 (Barus, 2010) mengenai "peranan Gendang guro-guro aron pada Kerja tahun di Masyarakat Karo di Desa Tanjung Barus Kecamatan Barus Jahe Kabupaten Karo". Hasil penelitiannya yaitu acara pesta kerja tahun merupakan acara hiburan bagi masyarakat Desa Tanjung Barus terlebih lagi acara Gendang guro-guro aron. Biasanya acara ini sangat diminati oleh muda-mudi yang sudah dewasa dan ikut berperan dalam acara tersebut. Selain itu Ary Arnanta (2011) melakukan penelitian tentang "Pesta kerja tahun Berteologi dalam Konteks Budaya Pesta kerja tahun Pada Batak Karo". Penelitiannya mengungkapkan tentang pemahaman masyarakat Karo tentang pesta kerja tahun sebelum dan sesudah masuknya agama ke Tanah Karo terlebih agama Kristen dan menjelaskan hubungan antara budaya dan agama dari segi agama Kristen Protestan (Arnanta, 2011)

Perbedaan penelitian terdahulu dengan yang saya lakukan adalah adanya beberapa perbedaan dalam pelaksanaan pesta kerja tahun dengan masyarakat lainnya. Pokok penelitian

Culture \& Society: Journal of Anthropological Research Vol. 2, No. 2, Th. 2020 
dapat dirumuskan yaitu makna simbol pesta kerja tahun. Teori yang dianggap relevan dalam penelitian ini adalah teori interpretevisme simbolik oleh Clifford Geertz. pandangannya tentang budaya adalah semiotik, maksudnya (1) mempelajari budaya berarti mempelajari aturan-aturan makna yang dimiliki bersama (2) hal-hal yang berhubungan dengan simbol dan dikenal oleh masyarakat yang bersangkutan. Simbol itu ditangkap (ditafsirkan) maknanya, dan dibagikan oleh dan kepada warga masyarakat setempat, kemudian diwariskan kepada generasi berikutnya (Geertz, 1992). Menurut Geertz, simbol adalah ojek, kejadian, bunyi bicara, atau bentuk-bentuk tertulis yang diberi makna oleh manusia. Manusia juga berkomunikasi sesama manusia dengan menggunkan tanda dan simbol dala lukisan, tarian, musik, arsitektur, mimik wajah, gerak-gerik, postur tubuh, perhiasan, pakaian, ritus, kekerabatan, nasionalitas, tata ruang, pemilikan barang, dan banyak lainnya (Saifuddin, 2002). Lebih jauh Clifford Geertz mengemukakan bahwa kebudayaan adalah (1) Sebagai suatu sistem keteraturan dari makna dan simbol-simbol, makna dan simbol tersebut individu-individu mendefenisikan dunia mereka, mendeskripsikan perasaanperasaan mereka, dan membuat penilaian mereka; (2) Suatu pola makna-makna yang ditransimisikan secara historis yang terkandung dalam bentuk-bentuk simbolik, melalui bentukbentuk simbolik tersebut manusia berkomunikasi, serta mengembangkan pengetahuan mereka dan bersikap terhadap kehidupan. (3) Suatu peralatan simbolik mengontrol perilaku, sumbersumber ekstrasomatik dari informasi. (4). Mengingat kebudayaan adalah suatu sistem simbol, maka proses kebudayaan harus dipahami, diterjemahkan dan diinterpretasikan.

\section{Metode Penelitian}

Penelitian ini dilakukan di desa Batu Karang Kecamatan Payung Kabupaten Karo. Alasan pemilihan lokasi penelitian adalah karena hampir di setiap upacara kerja tahun setiap tahun selalu dimeriahkan oleh acara gendang guro-guro aron. Selain itu hal yang menarik dari Desa Batu Karang ini adalah masyarakat Batu Karang mempunyai kesepakatan bahwa pesta kerja tahun dilakukan pada hari cukra dudu (lau setiap bulan Januari, meskipun pada tanggal tersebut bukan hari libur karena hari itu diyakini hari yang baik untuk melakukan pesta. Oleh karena itu peneliti memilih desa Batu Karang sebagai lokasi penelitian.

Penelitian ini dilakukan dengan pendekatan kualitatif. Pendekatan kualitatif merupakan penelitian yang menghasilkan data deskriptif mengenai kata-kata lisan maupun tertulis, dan tingkah laku yang dapat diamati dari orang-orang yang diteliti (Suyanto, 2011). Dengan pendekatan kualitatif informasi diperoleh berupa ungkapan dan penuturan langsung dari informan tentang pesta kerja tahun. Penelitian ini merupakan penelitian etnografi. Penelitian ini dikategorikan etnografi karena bermaksud melukiskan makna dari pesta kerja tahun sebagai salah satu upacara di tengah masyarakat. Memahami makna perbuatan dan kejadian orang yang bersangkutan dengan mengutamakan perspektif emik, realitas penelitian dipahami sesuai dengan perspektif masyarakat setempat (Native's Point of View) (Saifuddin, 2002). Tujuan penelitian etnografi adalah untuk memberi suatu gambaran holistik subjek penelitian dengan penekanan pada pemotretan pengalaman sehari-hari individu dengan mengamati dan mewawancarai mereka dan orang-orang lain yang berhubungan.

Data yang diperoleh lebih akurat dan peneliti juga bisa memperoleh data sebanyak mungkin dari informan. Teknik pemilihan informan dengan teknik purposive sampling. Jumlah informan secara keseluruhan adalah 34 orang. Data dikumpulkan dengan metode observasi partisipasi dan wawancara mendalam. Analisis data yang dilakukan dalam penelitian ini yaitu analisis etnografi dari Clifford Geertz yaitu hermeneutik data, menginterpretasikan data, dan interpretatif direpresentasikan (Saifuddin, 2002).

\section{Hasil dan Pembahasan}

Culture \& Society: Journal of Anthropological Research Vol. 2, No. 2, Th. 2020 


\section{Makna simbol upacara pesta kerja tahun (emik)}

\section{Makna Simbol Pemakaian Kalender Karo dalam Penetapan Hari Pesta Kerja tahun}

Kalender Karo ini sama dengan kalender konvensional (biasa) namun yang membedakannya adalah istilah-istilah adat pada tanggal dan hari tertentu seperti nama kalender. Setiap kegiatan harus mengikuti aturan menurut kalender tersebut seperti perhitungan melakukan perjalanan, pernikahan, perhitungan untuk upacara lainnya. Pada upacara pesta kerja tahun penanggalan cukra dudu adalah hari penting. Hal ini mendeskripsikan perasaan-perasaan masyarakat Karo akan ketakutan jika upacara pesta kerja tahun tidak mereka laksanakan sesuai dengan apa yang digariskan oleh para leluhur mereka. Sebagaimana penjelasan Bapak G. Bangun tokoh adat Desa Batu karang (Wawancara tanggal 28 Januari 2016) yang mengatakan bahwa pesta kerja tahun dari dahulu hingga saat ini selalu berpatokan kepada kalender Karo. Hal senada juga diungkapkan oleh Bapak Melam Tarigan Wawancara dengan Bapak Melam Tarigan (56 tahun) (wawancara tanggal 25, 26, 31 Januari 2016), beliau mengatakan bahwa hari pesta kerja tahun selalu berketepatan pada hari cukra dudu karena dianggap hari yang baik.

Pandangan Geertz tentang budaya berkaitan dengan aturan-aturan makna yang dimiliki bersama serta berhubungan dengan simbol-simbol yang dikenal oleh masyarakat yang bersangkutan. Masyarakat meyakini bahwa ada hari yang baik dan hari yang buruk untuk melakukan suatu acara besar, melakukan perjalanan dan kegiatan-kegiatan lainnya seperti penetapan hari cukra dudu sebagai hari yang baik bagi masyarakat desa Batu karang.

\section{Simbol Kepemimpinan dan Makna dari Pembentukan Panitia}

Pembentukan panitia merupakan tahap membuat tim kerja yang bertugas dan bertanggung jawab terhadap upacara pesta kerja tahun dari awal hingga akhir. Pembentukan panitia terlihat pada masyarakat Karo di Desa Batu Karang dilakukan secara musyawarah. Pada tahap awal pembentukan panitia biasanya dipilih anggota inti seperti ketua, sekertaris, dan bendahara. Panitia yang dibentuk untuk upacara pesta kerja tahun tanpa ada paksaan dan tekanan dari pihak manapun, termasuk juga tidak ada pembedaan suku bangsa maupun agama. Biasanya dalam pembentukan panitia ini kepala desa berperan sebagai tim penasehat dibantu oleh tua-tua adat yang mengerti adat dan organisasi. Jika dalam rapat terdapat kesalah pahaman atau ketidakpastian dalam mengambil keputusan biasanya ketua panitia meminta pendapat dan nasehat tim penasehat agara membantu memecahkan masalah tersebut.

Seperti yang diungkapkan oleh Kevin Karo-Karo (wawancara, tanggal 24, 25, 31 Januari 2016), pembentukan panitia dilakukan secara sukarela dan diajari untuk bertanggung jawab atas tugas yang diberikan dan pembentukan karakter untuk menjadi seorang pemimpin dan menjaga kumunikasi dengan organisasi yang sudah ada seperti kepala desa dan tua-tua adat. Diska (Wawancara tanggal 24 Januari 2016), beliau menjelaskan menjadi panitia kita diajari bagaimana menjadi pemimpin untuk bertanggung jawab terhadap tugas dan bagaimana meredam emosi.

Berdasarkan penjelasan informan di atas para panitia secara tidak langsung mengajari menjadi seorang pemimpin, menjadi orang yang bertanggung jawab terhadap tugas setiap devisi, di kepanitiaan juga para panitia diajari untuk meredam emosi. Selain itu juga mengajari para panirtia untuk menghargai dan menghormati orang yang lebih tua seperti kepala desa dan tua-tua adat dengan mengikutsertakan mereka menjadi tim penasehat.

Pandangan Geertz tentang budaya berkaitan dengan aturan-aturan makna yang dimiliki bersama serta berhubungan dengan simbol-simbol yang dikenal oleh masyarakat yang bersangkutan. Masyarakat desa Batu Karang terlihat bahwa pembentukan panitia secara sukarela atas kesadaran sendiri dan menjalankan tenggung jawab sebagai panitia tanpa pamrih.

\section{Makna Simbol Sumbangan Dana dari Masyarakat Desa Batu Karang}

Panitia bertugas menghimpun dana dari individu maupun kelompok yang akan menyumbang, dana yang dikumpulkan dari masyarakat, sponsor, proposal dan kerabat yang 
sudah lama merantau kemudian dana tersebut disalurkan sesuai dengan kebutuhan pelaksanaan. Biasanya setiap masyarakat Desa Batu Karang diwajibkan untuk menyumbang dengan jumlah yang sudah ditentukan, tapi jika masyarakat ingin menyumbang lebih dari target yang ditetapkan panitia akan memberikan kesmpatan untuk penyumbang menari di pentas sebagai tamu terhormat pada saat pesta kerja tahun. Sperti yang diungkapkan Kevin Karo-Karo mengatakan bahwa untuk pengumpulan dana biasanya membuat proposal dan membuat kutipan iuran per rumah, hal senada juga diungkapkan oleh seorang warga yang berinisial A. sembiring (60 Tahun) (wawancara tanggal 2 Februari 2016), beliau mengatakan bahwa tiap tahun ada pemungutan biaya ke rumahrumah warga.

Berdasarkan pernyataan yang disampaikan informan di atas dapat disimpulkan bahwa keikutsertaan masyarakat dalam membantu panitia dalam mengumpulkan dana dan secara tidak langsung masyarakat Desa Batu Karang diajari untuk bergotong royong untuk mengumpulkan biaya acara pesta kerja tahun. Clifford Geertz juga berbicara tentang makna dari simbol-simbol yang mendeskripsikan perasaan masyarakat melalui simbol-simbol tersebut, saling berkomunikasi serta mengembangkan pengetahuan mereka. Makna dari sumbangan dana dari masyarakat ini secara tidak langsung membuat masyarakat Desa Batu Karang bergotong royong untuk keberlangsuungan suatu kegiatan yang telah disepakati.

\section{Makna Simbol Ngerires dan Mantem}

Ngerires adalah proses memasak lemang pulut yang dilakukan secara bersama keluarga. Biasanya proses awalnya dilakukan oleh kaum ibu dan anak perempuannya dan dilanjutkan oleh kaum laki-laki untuk proses pemanggangan. Seperti yang disampaikan ibu R br Ginting (56 tahun) (wawancara tanggal 24 Januari 2016), bahwa membuat lemang harus ada kerja sama antara kaum perempuan dan laki-laki, kaum perempuan membuat bumbu untuk ngerires dan kaum laki-laki untuk membakar.

Ngerires memiliki sejarah dan makna yang panjang bagi masyarakat Karo karena sebelum tradisi agama besar masuk proses ngerires ini bertujuan sebagai sesajen untuk beru dayang yang akan dipersembahkan pada saat upacara pesta kerja tahun, namun seiring perkembangan zaman masyarakat Karo sudah menganut keyakianan agama besar (Kristen Protestan, Khatolik dan Islam) dam mereka mulai meninggalkan politeisme.

Mantem merupakan proses pembantaian hewan tertentu seperti babi, lembu dan lain-lain yang dijadikan sebagai lauk pada saat upacara pesta kerja tahun. Hidangan yang tersedia dapat memberikan kesan tersendiri bagi tamu yang datang bersilaturahmi wawancara dengan $\mathrm{R}$ br Ginting Setiap pesta kerja tahun selalu mengusahakan untuk ikut mantem agar ada lauk untuk tamu yang datang ke rumah. Babi merupakan makanan yang dianggap penting dan harus ada dalam setiap upacara-upacara adat. Sedangkan ikan, sapi dan ayam menjadi alternatif pilihan untuk lauk para tamu yang tidak memakan babi baik tamu yang muslim maupun tamu yang non muslim.

Kambing Hitam teori René Girard (Sindhunata, 2006), maka dapat disimpulkan bahwa ngerires dan mantem adalah salah satu ritus korban yang dibuat untuk kepentingan apa saja seperti untuk meminta hujan dan kesuburan tanah atau keberhasilan panen tapi tujuan ini adalah skunder yang primer adalah penghapusan kekerasan, pertikaian, rivalitas dan iri hati dalam masyarakat. Didalam proses ngerires dan mantem terdapat makna saling mendukung dan membantu untuk menyelesaikan proses ini.

\section{Makna Simbol Festival Tari Telu Serangkai dan Vocal Solo}

Festival tari telu serangkai dan vocal solo adalah festival yang memperebutkan piala dan uang tunai, untuk mengkuti festival ini peserta harus memenuhi persyaratan dari panitia seperti persyaratan untuk tari telu serangkai. Tujuan dari pembuatan festival ini untuk memeriahkan acara

Culture \& Society: Journal of Anthropological Research Vol. 2, No. 2, Th. 2020 
gendang guro-guro aron pada malam pertama. Peserta harus memakai kostum adat Karo baik untuk peserta yang perempuan dan laki-laki. Kostum para penari yang memakai pakaian adat Karo menunjukkan simbol-simbol tradisional seperti: tudung kelam-kelam yang dipakai oleh perempuan, baju terang bulan, uis nipes ragi barat, rudang mayang dan kampuh sedangkan untuk laki-laki ada beka buluhkelam-kelam untuk selempang dan kampuh.

Tari telu serangkai ini bertemakan pergaulan, pergaulan yang dimaksud adalah muda mudi Karo. Yakni pertemuan ramah tamah sepasang insan manusia yang berkenalan secara adat Karo, kemudian secara tutur muda mudi ini dapat berteman dekat (berpacaran) dan akhirnya mereka menjalin hubungan kasih hingga sampai kejenjang pernikahan. Sebagaimana penjelasan Bapak Benar Tarigan (60 tahun) seorang pelatih tari wawancara pada tanggal 31 Januari 2016), beliau menuturkan bahwa festival ini sengaja dibuat untuk melestarikan budaya Karo dan untuk mendidik anak-anaknya untuk mengerti tentang adat Karo mulai dari baju adat, berkenalan dalam adat Karo sampai tarian adat agar generasi muda lebih peduli kepada budaya Karo,

Selain festival telu serangkai ada juga lomba vocal solo. Vocal solo menarik minat penonton dan membuat generasi muda lebih banyak berpatisipasi. Secara tidak langsung festival vokal solo juga membentuk karakter pemuda untuk lebih berani tampil di depan publik serta melatih mental untuk lebih berani. Geertz mengungkapkan setiap aktivitas yang dijalankan oleh masyarakat mengandung makna. Makna tersebut diinterpretasikan dalam bentuk perilaku, jika dilihat lebih jauh analisis teori ini mengantarkan kita pada prespektif tentang makna dari aktivitas kesenian seperti menari dan bernyanyi.

\section{Makna Simbol dari Kirumah-Kirumah}

Kirumah-kirumah pada pesta kerja tahun adalah pergi berkunjung kerumah kerabat dalam rangka bersilaturahmi dalam suasana yang bahagia karena pada saat itu bertepatan hari ke dua pesta kerja tahun. Bersilaturahmi tidak hanya dilakukan oleh sanak saudara yang berada satu desa namun silaturahmi juga dilakukan oleh masyarakat Desa Batu Karang yang ada di desa lain maupun di desa perantauan yang datang berkunjung melihat kondisi sanak keluarganya sebagaimana penjelasan Ibu H br Ginting (wawancara tanggal 4 Februari 2016), yang mengatakan banyak tamu yang datang ke rumah kadang-kadang kerabat yang jauh juga datang dan disuguhkan makanan hal serupa juga dikatakan oleh Kristina Ketaren (wawancara pada tanggal 30 Januari 2016), yang berkunjung untuk bersilaturahmi ke rumah sahabatnya. Dari pernyataan di atas menggambarkan ada keterlibatan antara upacara pesta kerja tahun dengan tradisi silaturahmi. Masyarakat memilih pesta kerja tahun sebagai moment silaturahmi untuk mempererat tali persaudaraan antara kerabat. Geertz dalam teori interpretivisme simbolik maka kirumah-kirumah merupakan bentuk penafsiran untuk tetap mempertahankan silaturahmi masyarakat dengan tamutamu yang datang baik itu keluarga dekat maupun tamu yang tidak dikenal.

\section{Makna Simbol Gendang Gruo-Guro Aron.}

Gendang guro-guro aron merupakan acara nonton kibot dengan acara perkolong-kolong, yang sengaja diundang oleh panitia dalam rangka memeriahkan acara karena perkolong-kolong bisa mengisi acara semakin menarik dan menghibur, karena mereka selain mampu menari dan menyayi mereka juga bisa melawak atau melucu. Sebagai mana penjelasan Andi Bangun acara gendang guro-guro aron dilaksanakan semeriah mungkin dengan mengundang perkolong-kolong yang terkenal supaya banyak masyarakat menonton acara gendang guro-guro aron. Dengan adanya acara semakin meriah. Clifford Geertz denga teori interpretivisme simbolik sangat tepat untuk memahami makna-makna yang terdapat pada acara nonton kibot. Rasa terima kasih kepada penonton diwujudkan dalam bentuk hiburan perkolong-kolong.

\section{Makna Simbol Ngerebu}

Ngerebu adalah istilah yang sering dipakai oleh masyarakat Karo untuk memperlihatkan kondisi mereka yang sedang rehat sejenak dari seluruh aktivitas pekerjaan baik itu pekerjaan di 
rumah maupun di sawah kondisi ini merupakan kondisi peralihan setelah dua hari dua malam untuk menyegarkan badan dan pikiran kembali agar siap beraktivitas. Ngerebu dimanfaatkan oleh para petani untuk rehat sejenak untuk mengmbalikan stamina agar mereka siap menghadapi masa panen yang segera tiba.

\section{Makna Upacara Pesta Kerja Tahun (etik)}

\section{Pengataken Bujur man Dibata}

Pengataken bujur atau ucapan rasa terima kasih yang dirasakan oleh masyarakat Karo atas berkat dan rahmat atas panen mereka. pengataken bujur memperlihatkan rasa takut, rasa rendah hati, dan rasa lemah atas kekuatan yang ada termasuk kekuatan yang mengendalikan hasil panen para petani. Kepercayaan terhadap yang mengatur itu semua diperlihatkan dalam kebiasaan rasa bersyukur dan berterima kasih kepada pemberi rahmat atau berkah. Seperti penuturan Bapak Kongsi Sembiring (Wawancara tanggal 28 Januari dan 10 Februari 2016), ucapan rasa syukur kepada beru dayang yang menjaga padi agar padi tumbuh dengan bagus oleh sebab itu pada pesta kerja tahun dengan membuat sesajen untuk beru dayang. Tapi pada zaman sekarang setelah masyarakat batu karang sudah mempunyai keyakinan terhadap Tuhan (beragama) pesta kerja tahun ditujukan kepada Tuhan Yang Maha Esa yang telah menjaga kehidupan masyarakat.

Secara etik, peneliti melihat dan juga merasakan makna pengataken bujur man Dibata dari simbol aktivitas pada zaman dulu memeberikan sesajen kepada beru dayang (Malo, 1985). tapi zaman sekarang ini dapat ditanggap makna dari pengataken bujur man dinbata adalah ucapan terima kasih kepada Tuhan Yang Maha Esa Rasa dipanjatkan melalui doa bersama kelurga pada saat mereka makan bersama.

Dalam teori Geertz (1992) menganggap pandangannya tentang budaya adalah semiotik, maksudnya (1) mempelajari budaya berarti mempelajari aturan-aturan makna yang dimiliki bersama (2) hal-hal yang berhubungan dengan simbol dan dikenal oleh masyarakat yang bersangkutan. Simbol itu ditangkap (ditafsirkan) maknanya, dan dibagikan oleh dan kepada warga masyarakat setempat, kemudian diwariskan kepada generasi berikutnya.

\section{Mara Klesa}

Rasa takut akan mara klesa memiliki alasan yang kuat, walaupun tidak bisa dijelaskan, secara teori ada keterkaitan atau tidak antara kejadian aneh atau musibah yang terjadi pada masyarakat Karo selalu dikaitkan dengan pelaksanaan upacara pesta kerja tahun. Seperti yang diungkapkan oleh bapak Goreng Bangun (wawancara tanggal 26 Januari 2016), bahwa masyarakat Karo menaykini bahwa tata cara pelaksanaan pesta kerja tahun yang tidak dilakukan dengan baik tidak sesuai dengan adat akan ada mara klesa.

Sama halnya dengan Bapak Melam Tarigan secara pribadi juga mengalami bala ketika tahun 2011 silam keluarganya tidak membuat rires dikarenakan keadaan ekonomi keluarganya kurang baik dan anak-anak di tengah-tengah keluarga lagi membutuhkan banyak uang untuk tugas akhir/skripsi jadi Bapak Melam Taringan sepakat bersama istri tidak mengikuti acara pesta kerja tahun. Tapi keluarga Bapak Melam Tarigan jadi lebih kesulitan dalam segi ekonomi. Hal ini dapat disimpulkan bahwa masyarakat Karo memaknai mara klesa itu memiliki arti tersendiri jika tidak dilaksanakan akan ditimpa musibah

Dalam teori interpretivisme simbolik dikemukakan oleh Clifford Geertz kebudayaan didasarkan kepada penafsiran dan melalui penafsiran tersebut manusia mengontrol sikap dan tindakan, menjalankan suatu kebiasaan dan keyakinan yang diperoleh oleh individu dan diinterpretasikan dalam kehidupan mereka.

\section{Pesta Kerja Tahun Sebagai Hiburan}

Perayaan gendang guro-guro aron pada pertama dan malam kedua, memiliki kemeriahan yang berbeda jika pada malam pertama kemeriahannya dalam menonton festival pada malam kedua 
meriah karena dimeriahkan oleh perkolong-kolong dan artis Karo lainya. Gendang guro-guro aron pada malam kedua ini terlihat lebih meriah karena banyak masyarakat yang datang ke jambur untuk menonton acara gendang guro-guro aron dan menonton perkolong-kolong menari dan menyanyi menghibur penonton dengan candaan-candaan yang sengaja dilontarkan oleh pasangang perkolong-kolong seperti yang dituturkan oleh ibu $\mathrm{R} \mathrm{Br}$ Tarigan menurut beliau sangat meriah dan menghibur ada acara bernyanyi, menari, melawak itu yang membuat lupa sejenak pikiran-pikiran yang runyam. Dapat disimpulkan bahwa makna etik dari gendang guro-guro aron ini adalah sebagai hiburan (Tarigan, 2008).

\section{Sarana Pendidikan dan Pelestarian Budaya Karo}

Keberadaan acara gendang guro-guro aron juga menjadi sarana pendidikan bagi masyarakat Batu Karang terlebih bagi anak-anak yang sudah lahir dan besar di perantaauan. Acara pesta kerja tahun dan gendang guro-guro aron sangat berperan penting bagi mereka karena dipesta kerja tahun ini lah mereka mempunyai kesempatan mengenal bahasa, tarian, pakaian adat dan lain-lain. Seperti dikatakan oleh Bapak Ramin Ginting (wawancara tanggal 27 Januari 2016), pesta kerja tahun adalah kesempatan beliau untukmenjukkan dan mengajari anaknya tentang adat Karo. Dapat disimpulkan bahwa makna etik dari sarana pendidikan dan pelestarian budaya karo masyarakat Desa Batu Karang adalah antusiasme masyarakat mengikuti pelaksanaan pesta kerja tahun

\section{Tempat Mencari Jodoh}

Selain menjadi sarana pendidikan dan hiburan pesta kerja tahun juga bisa digunakan sebagian masyarakat terutama muda-mudi menjadi sarana mencari jodoh Seperti yang diungkapkan Arih Ginting (wawancara tanggal 25 Januari 2016) untuk mencari jodoh ke jambur karena banyak orang yang bercerita bahwa mereka ada yang mendapatkan jodoh pada saat menonton di jambur, dapat disimpulkan bahwa makna etik dari tempat mencari jodoh adalah tempat yang dimanfaatkan muda-mudi untuk mencari jodoh

Cliford geertz juga berbicara tentang makna dari simbol-simbol yang mendeskripsikan perasaan masyarakat melalui simbol-simbol tersebut, saling berkomunikasi serta mengembangkan pengetahuan mereka. Masyarakat Karo menafsirkan bahwa pelaksanaan pesta kerja tahun dapat menjadi tempat mereka menjodohkan atau mendap

\section{Kesimpulan}

Dari penelitian yang dilakukan diperoleh data bahwa keberadaan acara pesta kerja tahun memiliki maknna terhadap simbol-simbol yang terdapat pada upacara pesta kerja tahun. Makna yang muncul dari upacara yang pertama makna simbol upacara pesta kerja tahun terdiri dari 1). Makna simbol pemakaian kalender Karo dalam penetapan tanggal pesta kerja tahun. Pemakaian kelender ini menjadi ketetapan dalam masyarakat Desa Batu Karang bahwa wari cukra dudu adalah hari yang paling baik untuk melaksanakan pesta kerja tahun. 2) Simbol kepemimpinan dan makna dari pembentukan panitia. Simbol kepemimpinan menjelaskan tentang pembentukan karakter panitia dan hubungan kerja antara panitia dengan dewan desa dan tua-tua adat. 3) Makna dan simbol sumbangan dana dari masyarakat Desa Batu Karang, menjelaskan bahwa masyarakat sadar akan tanggung jawab sebagai masyarakat dan sebagaian masyarakat mempunyai simpati untuk memeriahkan acara pesta kerja tahun. 4) Makna simbol ngerires dan mantem, makna simbol ngerires dan mantem adalah sebagai perekat silaturahmi sesama masyarakat yang berbeda keyakinan dan saling membantu untuk menyelesaikan prosesi mantem dan ngerires. 5) Makna simbol festival tari telu serangkai dan vocal solo adalah ajang yang sengaja dibuat panitia untuk mengenalkan budaya Karo kepada anak-anak zaman sekarang yang akan menjadi generasi penerus. 


\section{Daftar Pustaka}

Arnanta, A. (20911). Pesta kerja tahun Berteologi dalam Konteks Budaya Pesta kerja tahun pada Batak Karo. STT-GMI.

Barus, N. E. (2010). Peranan Gendang guro-guro aron pada Kerja Tahun Masyarakat Karo di Desa Tanjung Barus Kecamatan Barus Jahe Kabupaten Karo. Unimed.

Geertz, C. (1992). Tafsir Kebudayaan. Yogyakarta: Kanisius.

http://www.google.com//repository.usu.ac.id/bitstream/artikel kerja tahun tradisi pada masyarakat Karo diakses tanggal 26 Januari 2016

http://www.scribd.com/doc/84281372/Gendang-guro-guro-aron-makalah\#scribd

Koentjaraningrat, K. (1992). Beberapa Pokok Antopologi Sosial. Jakarta: Dian Rakyat.

Malo, M. (1985). Metode Penelitian Sosial. Jakarta: Karunia.

Saifuddin, A. F. (2002). Antropologi Kontemporer. Jakarta: Kencana Media Group.

Sindhunata, S. (2006). Kambing Hitam Teori René Girard. Jakarta: Gramedia Pustaka Utama.

Suyanto, B. (2011). Metode penelitian sosial. Jakarta: Prenada Media Grup.

Tarigan, S. (2008). Dinamika Suku Batak Karo. Medan: Bina Media Perintis.

\section{Penjelasan istilah:}

1. Pagai beltek yaitu Keaadan padi sedang berisi/hamil

2. Wari mehuli nereh empo nuan galuh lape-lape, ndahi orang tua/ kalimbubu mengket rumah, erpangir kulau ( hari yang baik untuk menikah, menamam pembatas ladang, menjenguk orang tua/ orang yang dianggap sebagai kepala keluarga, memasuki rumah baru, membuang bala) biasanya hari cukra dudu ini dapat dilihat dari kelender Karo.

3. Ngerires merupakan kegiatan masyarakat Karo dalam menyambut kegiatan pesta kerja tahun yang berkaitan dengan penyediaan masakan khas pada waktu pesta kerja tahun yakni pembuatan lemang. Makanan ini biasanya disiapkan oleh setiap keluarga untuk menyambut tamu yang datang berkunjung ke rumah pada saat pesta kerja tahun.

4. Mantem merupakan acara memotong daging (babi dan sapi) baik secara kelompok maupun perorangan untuk bahan masakan atau lauk pada pesta kerja tahun.

5. Jambur adalah balai pertemuan desa yang digunakan oleh panitia upacara pesta kerja tahun sebagai tempat melaksanakan gendang guro-guro aron.

6. Jamuan makanan: tamu akan disuguhkan makanan khas pesta kerja tahun seperti tasak telu (ayam yang di sup dan dicincang-cincang dengan daun ubi dan kelapa), lomok-lomok (daging babi yang dimasak dengan menxampur bumbu gulai dengan darah babi), dan lemang (lemang adalah beras ketan yag dicampur dengan santan dan bumbu lemang lalu dimasukkan ke bambu dan proses pemasakannya dengan cara dibakar).

7. Ngerebu adalah istilah yang sering dipakai oleh masyarakat Karo untuk memperlihatkan kondisi mereka yang sedang rehat sejenak dari seluruh aktivitas pekerjaan baik itu pekerjaan dirumah maupu di sawah kondisi ini merupakan kondisi peralihan setelah dua hari dua malam untuk menyegarkan badan dan pikiran kembali agar siap beraktivitas seperti sedia kala.

8. Wari mehuli nereh empo nuan galuh lape-lape, ndahi orang tua/ kalimbubu mengket rumah, erpangir kulau (hari yang baik untuk menikah, menamam pembatas ladang, menjenguk orang tua/ orang yang dianggap sebagai kepala keluarga, memasuki rumah baru, membuang bala) biasanya hari cukra dudu ini dapat dilihat dari kelender Karo.

9. Tudung kelam-kelam adalahkain pabrik tekstil yang dicelup warna hitam menggunakan pewarna alami. Biasanya kain ini digunakan sebagai penutup kepala wanita Karo (tudung teger) waktu pesta adat pernikahan yang dipadupadankan dengan beka buluh atau uis nipes dan pesta guro-guro aron,.Kain ini juga digunakan sebagai tanda penghormatan kepada puang kalimbubu pada saat wanita lanjut usia meninggal dunia (morah-morah) Ukuran kain ini 169 × $80 \mathrm{~cm}$.

10. Baju terang bulan adalah baju perempuan pada zaman dahulu yang berbetuk seperti baju R.A Kartini berwarna hitam. Biasanya baju tersebut dipakai pada saat adat pesta dan hari-hari biasa, baju ini dipakai oleh anak gadis dan ibu-ibu.

Culture \& Society: Journal of Anthropological Research Vol. 2, No. 2, Th. 2020 
11. Uis nipes ragi barat adalah kain yang dipakai untuk selendang wanita pada upacara yang bersifat sukacita maupun dalam keseharian. Dipakai pada lapisan luar pakaian wanita bagian bawah (sebagai kain sarung) untuk kegiatan pesta sukacita yang diharuskan berpakaian adat lengkap. Uis nipes ragi barat ini berwarna merah dengan ukuran $144 \times 65 \mathrm{~cm}$.

12. Rudang mayang adalah bunga pinang yang disematkan di tudung kelam-kelam untuk menunjukkan yang memakai tudung itu adalah perempuan yang cantik dan baik diibaratkan seperti bunga pinang yang cantik.

13. Sarung.yang dipakai oleh perempuan dan laki-laki agar terlihat sopan.

14. Beka buluh adalah kain memiliki ciri Gembira, Tegas dan Elegan. Kain Adat ini merupakan Simbol Wibawa dan tanda kebesaran bagi seorang Putra Karo. biasanya kain ini digunakan Sebagai Penutup Kepala. Pada saat Pesta Adat, Kain ini dipakai Pria/putra Karo sebagai mahkota di kepalanya pertanda bahwa untuk dialah pesta tersebut diselenggarakan. Kain ini dilipat dan dibentuk menjadi Mahkota pada saat Pesta Perkawinan, Mengket Rumah (Peresmian Bangunan), dan Cawir Metua (Upacara Kematian bagi Orang Tua yang meninggal dalam keadaan umur sudah lanjut) kain beka buluh ini berukuran : 166 x $86 \mathrm{Cm}$ dan berwarna merah yang menandakn keberanian dan kegembiraan. 